\title{
Soft tissue sarcoma in Asia
}

\author{
Eileen Poon, Richard Quek \\ Division of Medical Oncology, National Cancer Centre Singapore, Singapore \\ Contributions: (I) Conception and design: All authors; (II) Administrative support: None; (III) Provision of study materials or patients: All authors; \\ (IV) Collection and assembly of data: All authors; (V) Data analysis and interpretation: All authors; (VI) Manuscript writing: All authors; (VII) Final \\ approval of manuscript: All authors. \\ Correspondence to: Eileen Poon. Division of Medical Oncology, National Cancer Centre Singapore, Singapore. \\ Email: eileen.poon.y.1@singhealth.com.sg.
}

\begin{abstract}
Sarcoma is an uncommon and heterogeneous group of malignancies linked by their mesenchymal origin. They are rare and account for $1 \%$ of adult cancers, and 10-20\% of adolescent and young adult (AYA) cancers. While there is good published literature on the incidence and distribution of sarcoma subtypes in the western populations, there is a paucity of data from Asia, particularly on the epidemiology, treatment and outcomes of STS in Asia. Formalized prospective national registries in soft tissue sarcoma (STS) are lacking and little is known about how sarcomas are treated and managed throughout the Asia-Pacific region. Due to geographical and varying affluence levels across over 50 countries, no single uniform guideline exists across Asia to inform of chemotherapeutic options. Any existent guidelines tend to be country-specific, reflecting resource availability and geographical limitation. To understand and improve STS care in Asia, one must appreciate the macroeconomics and healthcare structures in place and to work within the limitations imposed by them. Concurrently, there exists an urgency to develop strong sarcoma centres of excellence (SCE) across Asia to deliver state-of-art care to our patients. Equally important is the need to facilitate sarcoma education to patients and healthcare workers. Development of such centres is vital in improving clinical care as they provide high-quality sub-specialized care to patients within that geographical location, serve as reference centres for knowledge and education as well as nerve centres for care-coordination in a hub-andspoke model. Key to these centres of excellence is the sarcoma multi-disciplinary team (MDT). Studies have consistently shown that patients managed in high-volume sarcoma centres, by an expert sarcoma MDT, achieve better clinical outcomes. This report serves to highlight the challenges and opportunities of sarcoma care in Asia, map out a vision for the development of SCE across Asia and highlight the areas of potential collaboration between centres to advance the science of sarcoma.
\end{abstract}

Keywords: Asia sarcoma; adolescent and young adult cancer (AYA cancer); rare cancer in Asia

Submitted Jun 14, 2018. Accepted for publication Aug 01, 2018.

doi: $10.21037 /$ cco.2018.08.06

View this article at: http://dx.doi.org/10.21037/cco.2018.08.06

\section{Introduction to soft tissue sarcoma (STS)}

Sarcoma is an uncommon and heterogeneous group of malignancies linked by their mesenchymal origin. They are ubiquitous and may develop from connective tissues anywhere in the body (1-3). Sarcomas account for $1 \%$ of all adult cancers. In 2018, an estimated 13,040 people will be diagnosed with STS in the United States, with approximately 5,150 deaths (4). Based on the current WHO classification, there are now more than 50 different distinct subtypes of STS (4), with the most common aggressive STS being liposarcoma, leiomyosarcoma and undifferentiated pleomorphic sarcoma (3).

While there is good published literature on the incidence and distribution of sarcoma subtypes in the western populations, there is a paucity of data from Asia, particularly on the epidemiology, treatment and outcomes of STS in 
Asia (5). Formalized prospective national registries in STS are lacking and little is known about how sarcomas are treated and managed throughout the Asia-Pacific region (6).

While the general paradigm of sarcoma care may be similar in Asia as it is in the West, exact treatment guidelines are less established. They tend to be country-specific (7), reflecting resource availability within each country (7). This is particularly important and interesting considering the geography and heterogeneity of countries within Asia.

To understand and improve STS care in Asia, one must appreciate the macroeconomics and healthcare structures in place and to work within the limitations imposed by them. Concurrently, there exists an urgency to develop strong sarcoma centres of excellence (SCE) across Asia to deliver state-of-art care to our patients and facilitate sarcoma education to patients and healthcare workers. This report serves to highlight the challenges of sarcoma care in Asia, map out a vision for the development of SCE across Asia and highlight the areas of potential collaboration between centres to advance the science of sarcoma.

\section{The state of STS in Asia}

Reviewing the existing literature available for STS trends, there is a lack of outcomes and epidemiological data from Asia (5). There is no prospective data available, with most if not all, being retrospective data and are specific to a country (6,8-10). Ngan et al. had done a systematic review which gave a glimpse into the survival outcomes in STS (6).

In 2015, the STAR study (STS in the Asia-Pacific region) was reported, which described the epidemiology, treatment patterns and clinical outcomes of 635 patients with STS in 5 Asian countries. It demonstrated a median overall survival of 11.7 months in patients who presented with metastatic STS, a result comparable with outcomes from the West (5).

The predisposition to developing STS is not much different in Asia compared to our Western counterparts. Some of these include family cancer syndromes, previous exposure to radiotherapy or chemicals, HIV infection and autoimmune conditions (11-14). Family cancer syndromes include neurofibromatosis, Gardner syndrome, LiFraumeni syndrome, retinoblastoma and tuberous sclerosis. Due to the vast disparity in access to medical healthcare and knowledge, it is therefore not unexpected that some of these risk factors may not be known nor even diagnosed some parts of Asia. In general, the prognostic factors are similar to what is expected in the Western population. Malignancy grade, tumour type and size, site, tumour resectability, surgical margins achieved and presence of metastases at diagnosis are important prognostic factors (15-18). There are some tumor-specific retrospective studies, but these also show similar prognostic factors (19).

In the management of advanced STS, standard chemotherapy is still based on anthracyclines as the firstline treatment. Multi-agent chemotherapy is usually with the addition of ifosfamide, when a tumour response is felt to be potentially advantageous in a reasonably fit patient (15). There is now also the possible consideration of adding on an anti-PDGFRA agent, olaratumab to doxorubicin. Tap et al. had shown an improved progression-free survival (PFS) of about 2 months and an improved median overall survival of 12 months in their randomized phase 2 trial (20). Beyond first-line, guidelines suggest treatment that is driven by histology (15). Other recent therapeutic considerations include using palbociclib, a CDK4/6-inhibitor in patients with CDK4-amplified, well-differentiated or dedifferentiated liposarcoma, which showed an improved $10 \%$ PFS $(4,21)$.

\section{Medico-socio-economics and the healthcare structure in Asia}

There are about 50 countries that make up Asia with huge socio-economic discrepancies (5), both among and within countries. A country with lesser resources will be expected to have only the rudimentary basics of healthcare. Those with richer resources can afford for a more sophisticated healthcare structure. In Southeast Asia (SEA), delivering healthcare services to people dispersed across hundreds of islands or to remote areas is very challenging, made even more difficult when sub-specialized healthcare is needed (22). Recent analyses have drawn attention to the weaknesses of health care systems in low-and-middleincome countries (23).

Dr. Anne Mills, a British authority on health economics, published in 2014 a report identifying six levels of constraints that exists within any health care system from the community to the global level (23). In Table 1, we build upon this to reflect how this concept applies to sarcoma care in general and why SCE may help to mitigate some of these issues faced.

\section{SCE}

Development of SCE is vital in improving clinical care in patients. These centres provide high quality sub-specialized 
Table 1 Constraints in a healthcare system

\begin{tabular}{|c|c|c|c|}
\hline $\begin{array}{l}\text { Level of health care } \\
\text { system }\end{array}$ & Constraints & $\begin{array}{l}\text { How/why is sarcoma care } \\
\text { affected? }\end{array}$ & $\begin{array}{l}\text { How a sarcoma centre of } \\
\text { excellence can mitigate }\end{array}$ \\
\hline $\begin{array}{l}\text { Community and } \\
\text { household }\end{array}$ & $\begin{array}{l}\text { Lack of demand for effective } \\
\text { interventions }\end{array}$ & Less awareness & Create awareness \\
\hline \multirow[t]{4}{*}{ Service delivery } & \multirow[t]{3}{*}{ No standardization on quality of care } & Different standards of care & $\begin{array}{l}\text { Strengthen training and } \\
\text { supervision }\end{array}$ \\
\hline & & $\begin{array}{l}\text { Potentially sub-standard care is } \\
\text { delivered }\end{array}$ & Set standards of care \\
\hline & & - & Set guidelines \\
\hline & Inadequate drugs and medical supplies & $\begin{array}{l}\text { Without access to treatment, } \\
\text { unable to deliver care }\end{array}$ & $\begin{array}{l}\text { Strengthen public systems of } \\
\text { supply }\end{array}$ \\
\hline Government policy & $\begin{array}{l}\text { Limited communication and transport } \\
\text { infrastructure }\end{array}$ & $\begin{array}{l}\text { Unable to get the right } \\
\text { information and adequate care to } \\
\text { people }\end{array}$ & $\begin{array}{l}\text { Satellite centres increase access } \\
\text { for patients to seek specialized } \\
\text { healthcare. Helps to mitigate } \\
\text { problems of distance }\end{array}$ \\
\hline $\begin{array}{l}\text { Political and physical } \\
\text { environment }\end{array}$ & $\begin{array}{l}\text { Climatic and geographic predisposition } \\
\text { to disease, physical environment } \\
\text { unfavorable for service delivery }\end{array}$ & $\begin{array}{l}\text { Affects how care is delivered and } \\
\text { accessed by patients }\end{array}$ & $\begin{array}{l}\text { Brings medical care closer to } \\
\text { patients }\end{array}$ \\
\hline Global & $\begin{array}{l}\text { Fragmented governance and } \\
\text { management structures for global } \\
\text { health }\end{array}$ & $\begin{array}{l}\text { No treatment consensus } \\
\text { guidelines, leading to unequal } \\
\text { care }\end{array}$ & $\begin{array}{l}\text { Standardized good quality } \\
\text { treatment and sharing of best } \\
\text { practices }\end{array}$ \\
\hline
\end{tabular}

sarcoma care to patients within that geographical location, serve as reference centres for knowledge and education as well as nerve centres for care-coordination in a huband-spoke model. Key to these centres of excellence is the sarcoma multi-disciplinary team (MDT). Studies have consistently shown that patients managed in high-volume sarcoma centres, by an expert sarcoma MDT, achieve better clinical outcomes $(24,25)$.

\section{MDT}

A sarcoma MDT should typically consist of specialist sarcoma surgeons, radiation and medical oncologists, preferably a dedicated sarcoma pathologist, radiologist, clinical nurse, as well as palliative care specialists, allied health members and support staff. The MDT serves as a forum for this group of specialists to meet and discuss the management of each patient in a prospective fashion, prior to initiation of treatment, allowing for a coordinated actualization of a well thought-through plan from initial diagnosis to definitive treatment and follow-up. MDTs have become the accepted way of delivering modern cancer care and is key to the provision of high-quality individualized sarcoma care (2). In published studies, improvement in overall-and disease-free survival was observed in patients treated as part of a sarcoma MDT. In a population-based Canadian study, patients with limb STS treated by an MDT within 3 months of diagnosis had improved overall survival and reduced risk of amputation. A UK study also reported better overall survival for pediatric rhabdomyosarcoma treated in pediatric oncology centres compared to those treated in a general hospital (26). A strong sarcoma MDT could also serve as a platform to audit clinical practice, share best practices and enhance national, regional and international collaborations, which would all raise the quality of care in patients.

Of note, STS may be less common than epithelial cancers and there exists a need to justify the time and resources of a 
large sarcoma MDT to support the care of a more limited number of patients. Thus development of regional sarcoma referral centres or centres of excellence with established networks and referrals may be very important to maintain expertise and justify resources needed (26).

\section{Pathologist}

An accurate pathological diagnosis is vitally important in sarcoma management. A sarcoma pathological diagnosis must confirm the presence of sarcoma, indicate the grade and histological subtype of disease (27). However, it is well-recognized that pathological diagnosis is challenging in STS. Given the rarity of the disease, inappropriate medical management has been reported in more than $70 \%$ of sarcoma patients (28). Articles recommending histopathologic peer reviews for sarcoma have continued to appear in recent years (29-34). But this service is frequently not available in many parts of Asia. Clearly this is an issue given the frequency of misdiagnosis with carcinoma, melanoma, benign tumor, or even between sarcoma histological subtypes $(35,36)$. The reproducibility of STS diagnosis is also relatively poor across unfamiliar pathologists and the histopathological classification of this cancer in cancer registries is often inconsistent (31). With increasing sub-specialization, it is inevitable that histopathologists become less skilled outside their areas of practice. There is a consistent discrepancy between referring and expert diagnosis of approximately $25 \%$ for diagnosis and grade, and about $5 \%$ between a malignant and benign diagnosis $(29,33,35-44)$. The rate of falsenegative is underestimated as such reportedly benign cases will only be diagnosed when they recur or metastasize (29). A concordance study performed in Rhone-Alpes comparing primary diagnosis and systematic review by expert showed that $46 \%$ of diagnosis were modified at second reading and up to $19 \%$ of cases showed a discordance in the histological subtype (31). It was also found that only $56 \%$ had full concordance between primary diagnosis and second opinion with about $19 \%$ having a complete discordance. A centralized pathological review providing rapid and efficient help with access to molecular biology analysis is of vital importance in these rare tumors (31).

According to figures from the Royal College of Pathologists (RCP), in 2010, there were almost 1,100 diagnostic practicing pathologists in the UK. Assuming that the number of sarcoma cases was evenly distributed, each pathologist would see fewer than 2 cases of STS annually (29).
And with so many different histological subtypes, it may be nearly impossible for a single general pathologist to encounter all subtypes in adequate numbers in one lifetime (45). This argues strongly for the training of an expert sarcoma pathologist in each MDT. The European Society for Medical Oncology (ESMO) acknowledges the need for accurate diagnosis and states that a pathological expert second opinion is recommended in all cases where the original diagnosis was made outside of reference sarcoma centres (46). In the US, the National Comprehensive Cancer Network (NCCN) guidelines recommend that the pathologic assessment of biopsies should be carried out by an experienced sarcoma pathologist. This amount of experience is, however, undefined $(29,47)$. Similar recommendations are in preparation by the RCP of Australasia. In the UK, the National Institute for Health and Clinical Excellence (NICE) issued guidelines on the management of STS (26), recommending that all STS should be either first reported or reviewed by a specialist STS pathologist. Central to this all is sub-specialty training, exposure to sarcoma cases, both in terms of numbers and difficulty, and building of pathology networks in the region to share challenging cases. Anchored by good basic sarcoma pathology training, ancillary investigations oftentimes help confirm the diagnosis (48). These tests include immunohistochemical (IHC) stains and specific tests for molecular alterations. However, these are not routinely available and their use require experienced pathologists with relevant expertise (31). For example, the diagnosis of an atypical lipomatous tumor can be supported by demonstrating $M D M 2$ and $C D K 4$ amplification by Fluorescence in situ hybridization (FISH) or IHC. These are usually available only in specialized centers (29).

There is an ever-expanding array of molecular tests ranging from conventional morphology, karyotyping to deep exome sequencing (3). Morphology is basic requirement, while IHC testing is a useful tool in diagnosis and molecular studies, including chromosomal and translocation studies, are aspirational. The policies and guidelines governing use of these tests in each country needs to be carefully deliberated, weighed against the access, availability and effectiveness of therapeutics to allow for costeffective medicine across countries. To this end, the AsiaPacific sarcoma group put together a set of pathological recommendations according to individual country's resource availability (49). In the basic clinical setting, morphologic assessment with haematoxylin and eosin stains ( $\mathrm{H} \& \mathrm{E})$ is recommended. While in the limited setting, H\&E stains 
assisted by IHC workup would be available. In the enhanced setting, sarcoma-related translocation studies would be performed to aide in diagnosis. And finally in the most ideal of settings, histological examination would be further assisted by genomic analysis to guide molecularly-targeted treatment and research (49).

\section{Surgeon}

Surgery is a key component of the curative multi-modal treatment of localized STS and in selected patients with metastatic disease. While the aim of oncological surgery is good negative margins, there is no universally agreed numerical cut-off, though $1 \mathrm{~cm}$ is oftentimes suggested $(7,50)$. Challenging this mission is the rarity of tumor, ubiquitous primary location and potentially large tumor. Additionally, many STS are incidentally discovered following an excision of what was supposed to be a benign lump ("whoops surgery"). This initial excision is usually inadequate and a repeat proper oncological surgery is required. As such, delays in diagnosis is not uncommon (51). An American observational study of patients with STS noted that in non-specialist treatment centres, $59 \%$ of surgical resections reported as "wide" were found to contain residual disease on specialist pathological review (51).

To achieve best surgical outcomes for patients, key strategies include primarily, formal sarcoma surgical training, secondly, raising disease awareness amongst the public and fellow healthcare professionals to avoid "whoops surgery". Taking into consideration of each country's resources, there would be differences expected with types of surgical treatment availability. Basic surgical care may include amputation or wide resection by a general surgeon while maximal care would include surgeries being done by a dedicated multidisciplinary team (49).

\section{Medical oncologist}

The sarcoma medical oncologist has intimate knowledge of the disease particularly at the molecular level as well as the rapidly developing armamentarium of systemic treatment options personalized to the individual patient. While the role of the medical oncologist may be more limited in the setting of adjuvant treatment in STS (52-54), he/she occupies a key role in the palliative setting, directing care and managing systemic treatment.

Due to the complexity, geography and widely varying affluence of countries across Asia, no single uniform guideline exists to inform of chemotherapeutic options. First-line palliative chemotherapy option remains an anthracycline-based therapy and is accessible to most patients. Second-line and beyond is more heterogeneous and is subjected to healthcare reimbursements within each country. According to the set of resource-stratified guidelines drawn up by Asia-Pacific sarcoma investigators (49), the most basic of chemotherapy availability would include vincristine, cyclophosphamide, doxorubicin and dacarbazine (49). At the other end of the spectrum, would be agents such as pazopanib and trabectedin in addition to the more common drugs such as ifosfamide, gemcitabine, docetaxel and paclitaxel (49).

\section{Radiation oncologist}

(Neo)-adjuvant radiation is standard of care for resected high-risk STS of the extremities though its role in retroperitoneal sarcoma is less clear and the subject of a large international study (STRASS study) (55). Radiation treatment is accessible in different forms across Asia. Radiation therapy at the most basic level would include a simple field setup with a cobalt machine; in a limited setting delivered through linear accelerators. And in the maximal and enhanced settings the availability of intensity modulated radiotherapy (IMRT)/brachytherapy and proton beam/ carbon ion capabilities respectively $(49,56)$.

\section{Supportive and palliative care}

The diagnosis of sarcoma involves complicated treatment processes and decision-makings with potentially lifechanging functional outcomes. Many patients find it helpful when they are able to speak to patients who have gone through similar treatments. Practical needs resources are important to enable patients to continue living with their functional capability maximized.

Patients and their carers often need a variety of support, from symptom-management, to assessing social care and benefits, as well as specific needs such as orthoses and prosthetics (51). Psychological support is also important and the development of sarcoma-specific self-help groups and support groups should be encouraged (51). The 2004 Sarcoma UK survey found that sarcoma patients were not routinely offered formal psychosocial support, but those who attended counselling found it useful (51). Evidence from three systematic reviews considered in the NICE guidance on "Improving supportive and palliative care for 
adults with cancer" suggests that psychosocial interventions are useful for the reduction of anxiety in cancer patients $(51,57)$. In two small observational studies, peer support programmes were also viewed positively by patients, with many having decreased anxiety and depression (51). However, only $15 \%$ of the respondents to the Sarcoma UK survey had attended a sarcoma-specific patient support group (51).

Improved integration of palliative care services throughout the course of the illness will enhance quality of life for both patients and their carers (51). Integrated care is particularly important at the end of life, and the contribution of palliative care specialists will help to create a more appropriate balance between efforts to preserve life and the need for comfort, peace and support for close family members when it becomes clear that death is inevitable (51).

\section{Adolescent and young adult (AYA) sarcomas}

There is limited data on the incidence and epidemiology on AYA-specific sarcomas, largely contributed by the difficulty in obtaining such data. According to the SEER Database 1975-1999, approximately $70 \%$ of sarcomas diagnosed were in the age group 16-39 years old (58). Sarcomas comprise $10-20 \%$ of cancers in the young and the overall mortality is about $50 \%$, among the worst for any cancer type in AYAs $(59,60)$. Preliminary data from our centre showed that in the period between 2002 and 2016, we accrued 344 AYA sarcoma patients into our prospective database. Twenty-two percent had bony sarcomas, most commonly in the 16-19 years old age group, and 78\% had STS, most commonly in the 35-39 years old age group. Among AYA STS patients, the 3 most common sarcomas subtypes were synovial sarcomas, liposarcomas and dermatofibrosarcoma protuberans (61). Up to $40 \%$ was lost to follow-up.

Treatment outcomes in AYA patients have not improved significantly nor kept pace with the rest of oncology over the past 20 years (62). There is evidence to suggest that AYAs with sarcomas do substantially worse than children. 5 -year overall survival for both osteosarcoma and EWS in AYAs between 1983-2003 is 45\%, compared to $76 \%$ for children under 15 (60). There are specific concerns with this age group, with psychological distress being significantly greater compared to the other counterparts. They face serious problems related to loss of fertility, disruptions of education and careers, limitations in social interactions, psychosocial distresses in addition to the threat to their mortality. Some of the more straightforward issues such as adhering to clinic visits and treatment schedules can be made more complicated in an AYA patient as they balance between managing their young careers and staying on treatment (62). Additionally, AYA sarcomas arising from limbs may entail aggressive surgery including amputation leading to psychological distresses, body image issues as well as physical limitations.

In a recent UK survey of an AYA group, $42 \%$ of those with STS said they had visited their general practitioner more than 5 times before they were referred to a hospital (51). Similarly, in an American study, AYA sarcoma patients reported a mean of 4.85 physician visits before a referral to a specialist unit for a bone or STS was made (51). This clearly highlights the issue of delayed diagnosis in AYA sarcoma patients and the urgent need to raise awareness amongst the public and fellow healthcare workers about this disease. The field of AYA is in its infancy, even more so in Asia. Having an AYA service in the sarcoma MDT greatly enhances care to patients.

\section{Genetics service}

Various cancer syndromes are associated with sarcomas, including Li-Fraumeni, familial adenomatous polyposis and Gardner's syndromes. The incidence rates of such genetic diseases in the Western population are well published but is less known in Asia. Germline sarcoma mutations in patients were found to be more common than previously thought. The largest study to-date, the International Sarcoma Kindred study (ISKS), performed in 1,162 probands of both Caucasian and Asian descent, interrogated germline mutations in sarcoma patients and found that $55 \%$ of sarcoma patients harbor putatively pathogenic monogenic and polygenic variation in known and novel cancer genes (63). While work from our group focused on a cohort of 66 Asian patients younger than 50 years of age and found that $13.6 \%$ of patients had at least one predicted pathogenic germline mutation (64). Collectively, these data suggest that germline mutation in sarcoma patients may be higher than anticipated and lends strong support to the inclusion of a cancer genetics service into the sarcoma MDT.

\section{Accreditation process}

Accreditation, at the level of the MDT as well as individual clinical services, is an essential step to ensure standards are maintained and guidelines are adhered to. For example, the NICE guidelines recommend that an STS pathologist is one 
who regularly reports STS as a significant component of his/her workload. In addition, the pathologist should participate in external quality assessment (EQA) and be a member of a properly constituted sarcoma MDT. The MDT should also meet requirements to ensure that standards are achieved and maintained. This can be potentially audited at the basic level by the minimum number of patients discussed/ managed per year and complexity of cases discussed (51).

\section{Treatment guidelines}

Several international sarcoma guidelines are available and commonly used by practicing clinicians. They include the NCCN and ESMO guidelines $(4,46)$. However, these international guidelines do not take into account resource limitations that exist in Asia, between countries, and sometimes within disparate geographical locations within a country. As alluded to earlier, investigators in the region published a set of resource-stratified guidelines for the management of sarcoma in the Asia-Pacific region, providing a framework of care at each resource level and serve as a roadmap for sites to aspire to in their developmental process. In Singapore, there also exists the existence of the SCAN (Singapore Cancer Network) guidelines to provide some guidance on the diagnosis and management of sarcomas (7).

\section{Sarcoma collaborations}

STSs are rare and heterogeneous tumors. To improve clinical care, education and research, one needs to exploit opportunities, both regionally and internationally for collaboration.

\section{Clinical care collaboration}

Given the complexity and heterogeneity of sarcoma, the management requires integrated care. The ability to strengthen international collaborations result in maximization of resources, thereby improving care for our patients (65). This allows better and greater access to drugs across Asia, and also allow a better understanding of how these drugs work for our patients. In addition, international collaboration also allows sharing of the most up-to-date diagnostic and treatment possibilities, ultimately benefitting the patient.

In the real world, the SCE complete with its MDT do not exist on its own. It is the hub which directs and strengthens all sarcoma-related care activities in the community. Hence building a strong collaborative network and expedited referral process (where necessary) are key factors in improving patient care. Collaboration allows integration pre-and-post operatively to allow precise coordination of chemotherapy, radiotherapy and surgery (66). This approach not only allows best care for patients $(24,67)$, but at the same time allows for the concentration of these rare cancers into specific centres to continually hone the skills of sarcoma clinicians.

\section{Educational collaborations}

Education in sarcoma can be looked upon at three levels, namely general public, community health and professional levels.

For the public, efforts have been largely singular and country-specific. There needs to be proper public education to minimize patient-related delay in diagnosis. In a Belgian study, $47 \%$ of STS patients had a delay of more than 1 month before seeking medical advice, with a median delay of 4 months. In a Dutch study, 36\% of patients with retroperitoneal STS waited for more than 6 months before seeing a doctor (51).

At the community health level, inaccurate and late diagnoses lead to mismanagement in $70 \%$ of patients with a number receiving wrong treatment (2). It is therefore important to raise awareness and knowledge of sarcomas within the community (2). Non-sarcoma specialists need a reliable source of information and network of care for their patients (51). Various efforts have been made to raise sarcoma awareness in healthcare and allied health professionals, but these have not been uniform. It is estimated that a GP is only likely to see one or two sarcomas in his/her career (24). In a study of referrals to a UK specialist STS unit, 20\% had more than a 3-month delay, with the median being 14 months. The most frequent reason was a lack of clinical suspicion. A second UK study showed that a referral from the primary doctor took 7.5 months (51). Educating our fellow colleagues will hopefully decrease referral delays.

At the professional level, there exists an unmet need across Asia to have sarcoma-specific forums where sarcoma experts and specialists meet to share knowledge on the subject. There is also a lack of preceptorships where trainees can learn from. Such meetings are beneficial to create awareness and educate our fellow colleagues.

The biannual Asia-Pacific Musculoskeletal Tumor Society (APMSTS) meeting, with an orthopedic oncology 
focus, is one such example. The annual Singapore Sarcoma Symposium, initiated in 2013, focuses on a broad multidisciplinary range of sarcoma topics, for the local and regional sarcoma community. These efforts are invaluable in promoting the sharing of knowledge and education of our fellow healthcare professionals and allied health partners. Additionally, sarcoma-specific preceptorship programs catered for practicing clinicians are highly effective tools for sharing state-of-art medical knowledge with fellow colleagues. To this end our group hosted 2 programs in 2017. The first was a clinically focused interactive preceptorship built around an MDT framework on the various sarcoma subtypes. While the other was a sarcoma pathology focused event for regional and international sarcoma pathologists to share, learn and network, paving the way for future collaborations.

One commendable healthcare professionals-targeted education effort would be the Sarcoma Policy Checklist. This is a joint effort by a multi-stakeholder group of experts from the medical, patient advocacy and pharmaceutical industry fields. It aims to help policymakers close the gap in access to high quality information and care for sarcoma patients across Europe (2). In the UK, EQAs are as of the UK National Orthopedic Pathology EQA scheme. The scheme provides 2 circulations a year with relevant questions to encourage ongoing education (26). Training should be developed and provided for all members of both the core and extended sarcoma MDT (51).

\section{Research collaboration}

In research of rare tumors like sarcoma, collaboration is key. Management of sarcomas is difficult due to limited information on natural history. Continuous prospective long-term databases are important to obtain knowledge for rare tumors (68). This is consistent both in the Western and Asian populations. Currently there is a paucity of prospective data coming out of Asia (6). Across Asia, national registries are limited for rare tumors like sarcoma. Current Asian studies tend to be small, are usually singlecentred and retrospective. This makes it difficult to draw firm conclusions.

Research is made even more challenging by the heterogeneity and reproducibility in histological diagnoses. To produce robust Asian data with large sample size, there exists a need to build regional and international collaborations to pool and share data. Of particular interest would be genetic differences in Asian patients with regards to disease incidence, response and tolerance to treatment.

In this respect the Asian Sarcoma Consortium (ASC), was formed to bring together the Asian sarcoma research community. In its inaugural efforts, the group reported on the epidemiology and real world treatment of a large cohort of 423 patients with angiosarcoma from 8 sites in 6 Asian countries (69). Additionally the STAR study (5) was an Asian multi-centred observational study initiated to describe epidemiology, treatment patterns and clinical outcomes in STS patients diagnosed between 2006-2010. More efforts must be placed into building formalized research collaborations within Asia to advance the science of sarcoma.

\section{Conclusions}

In summary, STS is an uncommon and heterogeneous group of malignancies. Due to the unique and disparate socio-economic statuses and healthcare systems of the individual countries in Asia, it has made understanding this disease in Asian context even more difficult. Most data present are largely country-specific and retrospective.

We propose the development of SCEs across Asia. This will hopefully allow high-quality sub-specialized sarcoma care to patients, especially to areas where access may particularly be difficult. SCEs should include:

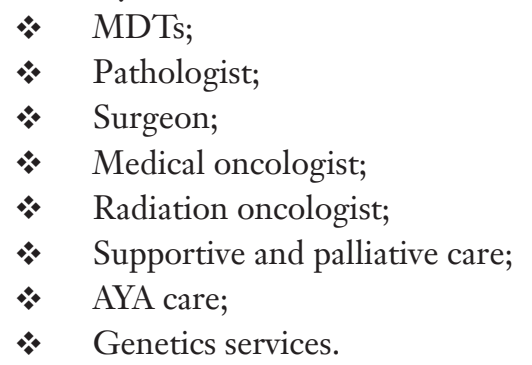

SCEs should be responsible for the development of region-specific treatment guidelines and the accreditation process. This will ensure standards are maintained and guidelines adhered to.

In order to advance sarcoma care in Asia, no individual country can do this alone. There are multiple avenues possible for collaboration, and these should be done regionally and internationally:

* Clinical care collaboration;

* Educational collaborations (general public, community health and professional level);

* Research collaboration.

This report serves to highlight the challenges and opportunities of sarcoma in Asia. Asia is huge and diverse. 
While the inherent geographical and socio-economic factors may be outside the scope of this report, there are however many opportunities to improve clinical care, expertise, education and research in sarcoma within Asia. The sarcoma MDT within centres of excellence serves as the foundation from which we build upon. National guidelines to set standards of care and prospective databases to capture real world data are useful tools to understand and better manage this disease. While the ASC has paved the way in the past 5 years with fruitful collaborations, more will need to be done in order to ensure advancements in sarcoma care continue. Moving forwards, formalized national and Asia-wide research collaborative networks should be set up to provide the much-needed platforms for us to study this unique disease in the Asian setting.

\section{Acknowledgements}

None.

\section{Footnote}

Conflicts of Interest: The authors have no conflicts of interest to declare.

\section{References}

1. Jo VY, Fletcher CD. WHO Classification of soft tissue tumours: an update based on the 2013 (4th) edition. Pathology 2014;46:95-104.

2. Lilly. The Sarcoma Policy Checklist. 2017, February.

3. Fletcher CDM, Sundaram M, Rydholm A, et al. Soft tissue tumours: Epidemiology, clinical features, histopathological typing and grading. World Health Organization classification of tumors. Pathology and genetics of tumours of soft tissue and bone. IARC Press, 2002:9-18.

4. NCCN. NCCN Guidelines Version 2.2018 Soft Tissue Sarcoma. NCCN Guidelines 2018.

5. Quek RH, Farid M, Wang E, et al. Epidemiology, treatment (tx) patterns and outcomes in Asian soft tissue sarcoma (STS) patients: Results from the Soft Tissue Sarcoma in the Asia Pacific Region (STAR) study. J Clin Oncol 2015;33:10549.

6. Ngan R, Wang E, Porter D, et al. Soft-tissue sarcomas in the Asia-Pacific region: a systematic review. Asian Pac J Cancer Prev 2013;14:6821-32.

7. Singapore Cancer Network (SCAN) Sarcoma Workgroup. Singapore Cancer Network (SCAN) Guidelines for the Initial Evaluation, Diagnosis, and Management of Extremity Soft Tissue Sarcoma and Osteosarcoma. Ann Acad Med Singapore 2015;44:474-83.

8. Ohtsuka H, Nagamatsu S. Changing trends in the number of deaths from soft tissue sarcoma in Japan, 1955-2002. Eur J Cancer Care (Engl) 2006;15:133-7.

9. Ogura K, Higashi T, Kawai A. Statistics of soft-tissue sarcoma in Japan: Report from the Bone and Soft Tissue Tumor Registry in Japan. J Orthop Sci 2017;22:755-64.

10. Yuan XJ, Chan GC, Chan SK, et al. Treatment outcome of rhabdomyosarcoma in Hong Kong Chinese children. Hong Kong Med J 2008;14:116-23.

11. American Cancer Society. Risk Factors for Soft Tissue Sarcomas. 2018.

12. Cancer Net. Sarcoma, Soft Tissue: Risk Factors. 2017.

13. Available online: https://www.nccs.com.sg/PatientCare/ WhatisCancer/TypesofCancer/Pages/Sarcoma-Cancer. aspx

14. Burningham $Z$, Hashibe $M$, Spector $L$, et al. The epidemiology of sarcoma. Clin Sarcoma Res 2012;2:14.

15. Casali PG, Abecassis N, Bauer S, et al. Soft tissue and visceral sarcomas: ESMO-EURACAN Clinical Practice Guidelines for diagnosis, treatment and follow-up. Ann Oncol 2018. [Epub ahead of print].

16. TNM Classification of Malignant Tumours, 8 th edition. Oxford: John Wiley \& Sons, Inc., 2016.

17. Zagars GK, Ballo MT, Pisters PW, et al. Prognostic factors for patients with localized soft-tissue sarcoma treated with conservation surgery and radiation therapy: an analysis of 1225 patients. Cancer 2003;97:2530-43.

18. Koea JB, Leung D, Lewis JJ, et al. Histopathologic type: an independent prognostic factor in primary soft tissue sarcoma of the extremity? Ann Surg Oncol 2003;10:432-40.

19. Wisanuyotin T, Radapat K, Sirichativapee W, et al. Prognostic factors and clinical outcomes in synovial sarcoma of the extremities. Asia Pac J Clin Oncol 2013;9:80-5.

20. Tap WD, Jones RL, Van Tine BA, et al. Olaratumab and doxorubicin versus doxorubicin alone for treatment of softtissue sarcoma: an open label phase $1 \mathrm{~b}$ and randomized phase 2 trial. Lancet 2016;388:488-97.

21. Dickson MA, Tap WD, Keohan ML, et al. Phase II trial of the CDK4 inhibitor PD0332991 in patients with advanced CDK4-amplified well-differentiated or dedifferentiated liposarcoma. J Clin Oncol 2013;31:2024-8.

22. Staff BAE. Is Asia-Pacific Health Care Accessible and Affordable? BRINK 2017. Available online: https://www. brinknews.com/asia/is-asia-pacific-healthcare-accessible- 
and-affordable/

23. Mills A. Health care systems in low- and middle-income countries. N Engl J Med 2014;370:552-7.

24. Benson C, Judson I. Role of expert centres in the management of sarcomas--a UK perspective. Eur J Cancer 2014;50:1951-6.

25. Gutierrez JC, Perez EA, Moffat FL. Should soft tissue sarcomas be treated at high-volume centers? An analysis of 4205 patients. Ann Surg 2007;245:952-8.

26. Improving Outcomes for people with sarcoma. The manual. National Institute for Health and Clinical Excellence, 2006.

27. Demetri GD, Baker LH, Beech D, et al. Soft tissue sarcoma clinical practice guidelines in oncology. J Natl Compr Canc Netw 2005;3:158-94.

28. Fletcher CD. WHO classification of tumors. Pathology and genetics. Tumours of Soft Tissue and Bone. IARC Press, 2002.

29. Fisher C. Diagnosing sarcomas: the role of experience. Diagn Histopathol 2011:333-9.

30. Mastrangelo G, Coindre JM, Ducimetiere F, et al. Incidence of soft tissue sarcoma and beyond: a populationbased prospective study in 3 European regions. Cancer 2012;118:5339-48.

31. Lurkin A, Ducimetiere F, Vince DR, et al. Epidemiological evaluation of concordance between initial diagnosis and central pathology review in a comprehensive and prospective series of sarcoma patients in the Rhone-Alpes region. BMC Cancer 2010;10:150.

32. Lehnhardt M, Daigeler A, Hauser J, et al. The value of expert second opinion in diagnosis of soft tissue sarcomas. J Surg Oncol 2008;97:40-3.

33. Thway K, Fisher C. Histopathological diagnostic discrepancies in soft tissue tumours referred to a specialist centre. Sarcoma 2009;2009:741975.

34. Ray-Coquard I, Montesco MC, Coindre JM, et al. Sarcoma: concordance between initial diagnosis and centralized expert review in a population-based study within three European regions. Ann Oncol 2012;23:2442-9.

35. Arbiser ZK, Folpe AL, Weiss SW. Consultative (expert) second opinions in soft tissue pathology. Analysis of problem-prone diagnostic situations. Am J Clin Pathol 2001;116:473-6.

36. Meis-Kindblom JM, Bjerkehage B, Bohling T, et al. Morphologic review of 1000 soft tissue sarcomas from the Scandinavian Sarcoma Group (SSG) Register. The peerreview committee experience. Acta Orthop Scand Suppl 1999;285:18-26.
37. Harris M, Hartley AL, Blair V, et al. Sarcomas in north west England: I. Histopathological peer review. Br J Cancer 1991;64:315-20.

38. Presant CA, Russell WO, Alexander RW, et al. Softtissue and bone sarcoma histopathology peer review: the frequency of disagreement in diagnosis and the need for second pathology opinions. The Southeastern Cancer Study Group experience. J Clin Oncol 1986;4:1658-61.

39. Coindre JM, Nguyen BB, Goussot JF, et al. Histological changes after chemotherapy of soft tissue sarcomas in the adult. Ann Pathol 1985;5:95-9.

40. Coindre JM, Trojani M, Contesso G, et al. Reproducibility of a histopathologic grading system for adult soft tissue sarcoma. Cancer 1986;58:306-9.

41. Katenkamp D. Cellular heterogeneity. Explanation for changing of tumor phenotype and biologic behavior in soft tissue sarcomas. Pathol Res Pract 1988;183:698-705.

42. Randall RL, Bruckner JD, Papenhausen MD, et al. Errors in diagnosis and margin determination of softtissue sarcomas initially treated at non-tertiary centers. Orthopedics 2004;27:209-12.

43. Shiraki M, Enterline HT, Brooks JJ, et al. Pathologic analysis of advanced adult soft tissue sarcomas, bone sarcomas, and mesotheliomas. The Eastern Cooperative Oncology Group (ECOG) experience. Cancer 1989;64:484-90.

44. Westra WH, Kronz JD, Eisele DW. The impact of second opinion surgical pathology on the practice of head and neck surgery: a decade experience at a large referral hospital. Head Neck 2002;24:684-93.

45. Chintamani. Soft tissue sarcomas-the pitfalls in diagnosis and management!! Indian J Surg Oncol 2011;2:261-4.

46. Casali PG, Blay JY; ESMO/CONTICANET/ EUROBONET Consensus Panel of experts. Soft tissue sarcomas: ESMO Clinical Practice Guidelines for diagnosis, treatment and follow-up. Ann Oncol 2010;21 Suppl 5:v198-203.

47. NCCN. NCCN Practice Guidelines in Oncology, Soft Tissue Sarcoma v2. 2010.

48. The Current State of Molecular Pathology in Diagnosing Sarcomas. Liddy Shriver Sarcoma Initiative. Available online: http://sarcomahelp.org/articles/molecularpathology-sarcoma.html

49. Lewin J, Puri A, Quek R, et al. Management of sarcoma in the Asia-Pacific region: resource-stratified guidelines. Lancet Oncol 2013;14:e562-70.

50. Baldini EH, Goldberg J, Jenner C, et al. Long-term outcomes after function-sparing surgery without 
radiotherapy, for soft tissue sarcoma of the extremities and trunk. J Clin Oncol 1999;17:3252-9.

51. Guidance on Cancer Services. Improving Outcomes for People with Sarcoma: The Manual. National Institute for Health and Clinical Excellence, 2006 March.

52. Brunello A. Adjuvant chemotherapy for soft tissue sarcomas: a 10-year mono-institutional experience. J Cancer Res Clin Oncol 2016;142:679-85.

53. Bajpai J, Susan D. Adjuvant chemotherapy in soft tissue sarcomas... Conflicts, consensus, and controversies. South Asian J Cancer 2016;5:15-9.

54. Adjuvant chemotherapy for localised resectable softtissue sarcoma of adults: meta-analysis of individual data. Sarcoma Meta-analysis Collaboration. Lancet 1997;350:1647-54.

55. EORTC. Surgery With or Without Radiation Therapy in Untreated Nonmetastatic Retroperitoneal Sarcoma (STRASS).

56. von Mehren M, Randall RL, Benjamin RS, et al. Soft Tissue Sarcoma, Version 2.2014. J Natl Compr Canc Netw 2014;12:473-83.

57. National Institute for Clinical Excellence. Improving supportive and palliative care for adults with cancer. NICE Cancer Service Guidance, 2004.

58. Bleyer A, O'Leary M, Barr R, et al. editors. Cancer Epidemiology in Older Adolescents and Young Adults 1529 Years of Age, Including SEER Incidence and Survival: 1975-2000. Bethesda, MD: National Cancer Institute, 2006.

59. Thomas D, Whyte S, Choong P. Australian Sarcoma Study Group: development and outlook. Available online: https://cancerforum.org.au/forum/2009/march/australiansarcoma-study-group-development-and-outlook/

Cite this article as: Poon E, Quek R. Soft tissue sarcoma in Asia. Chin Clin Oncol 2018;7(4):46. doi: 10.21037/ cco.2018.08.06
60. Thomas D, Whyte S, Choong P. Australian Sarcoma Study Group: Development and Outlook. Cancer Forum 2009;33:25-8.

61. Goh W EPea. Adolescent and Young Adult (AYA) Sarcomas: a review of 344 patients seen at National Cancer Centre Singapore. CTOS Abstract 2017. Available online: https://www.ctos.org/Portals/0/PDF/2017\%20CTOS\%20 Final\%20Program.pdf

62. Coccia PF, Pappo AS, Beaupin L, et al. Adolescent and Young Adult Oncology, Version 2.2018, NCCN Clinical Practice Guidelines in Oncology. J Natl Compr Canc Netw 2018;16:66-97.

63. Ballinger ML, Goode DL, Ray-Coquard I, et al. Monogenic and polygenic determinants of sarcoma risk: an international genetic study. Lancet Oncol 2016;17:1261-71.

64. Chan SH, Lim WK, Ishak NDB, et al. Germline Mutations in Cancer Predisposition Genes are Frequent in Sporadic Sarcomas. Sci Rep 2017;7:10660.

65. Trimble EL, Abrams JS, Meyer RM, et al. Improving cancer outcomes through international collaboration in academic cancer treatment trials. J Clin Oncol 2009;27:5109-14

66. Sarcoma Care: Meeting of the Minds, 2016.

67. Dangoor A, Seddon B, Gerrand C, et al. UK guidelines for the management of soft tissue sarcomas. Clin Sarcoma Res 2016;15;6:20.

68. Brennan MF, Antonescu CR, Moraco N. Lessons learned from the study of 10,000 patients with soft tissue sarcoma. Ann Surg 2014;260:416-21; discussion 421-2.

69. Quek R. Epidemiology, real world treatment and outcomes of 423 patients (pts) with angiosarcoma (AS) in Asia: A report from the Asian Sarcoma Consortium (ASC). Ann Oncol 2016;27:mdw597.001. 